\title{
O TEXTO LITERÁRIO NA AULA DE LE - CONSTRUINDO UM LUGAR ALTERNATIVO PARA A PRÁTICA DA AGÊNCIA DISCENTE/DOCENTE ${ }^{1}$
}

\author{
Janice Inês Nodari ${ }^{1}$
}

\section{Resumo}

Este artigo se propõe a discutir a formação de professores de inglês facilitada pelo exercício da agência híbrida discente/docente resultante de uma experiência de trabalho com a estrutura da língua inglesa tendo, como ponto de partida, contos curtos na referida língua. Entende-se que, como futuros professores, os profissionais de língua inglesa podem ser bem sucedidos se souberem fazer uso das ferramentas culturais a que tem acesso, dentre elas, o texto literário. A proposta contou com a aplicação de um questionário aos discentes/docentes após a experiência, e mostrou que esta prática pedagógica foi plausível, factível e executável apesar de todos os desafios inerentes a ela, e proporcionou momentos de reflexão sobre a prática e a formação inicial de discentes/docentes do curso de Letras da UFPR.

Palavras chave: Formação de professores. Agência híbrida. Experiência. Discentes/docentes. Contos em língua inglesa.

\begin{abstract}
This paper proposes a discussion on the formation of English teachers facilitated by the exercise of the hybrid student/teacher's agency resulting from a work experience with the structure of the English language having, as a starting point, short stories in English. As teachers to be, the professionals of the English language may be successful if they know how to use the several cultural tools available, among them, the literary text. The proposal made use of a questionnaire answered by the students/teachers after the experience, and showed that it is a plausible, feasible and executable pedagogical practice despite all the challenges related to it, and made possible some moments of reflection upon the practice and initial formation of the students/teachers of the Letras course at UFPR.
\end{abstract}

Keywords: Teachers' formation. Hybrid agency. Experience. Students/teachers. Short stories in English.

\section{Introdução}

É senso comum que a língua inglesa é uma língua global (CRYSTAL, 2010), que atingiu este status não pelo número de falantes nativos, mas pelo aumento no número de pessoas que acredita ser benéfico aprender inglês como língua adicional (MCKAY, 2003, p. 1). As formas de se aprender a língua, porém, e todo o conhecimento que precisa ser

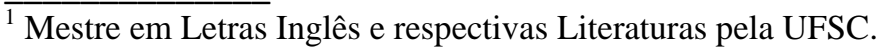

Professora substituta da UFPR, junto ao Departamento de Letras Estrangeiras Modernas da Universidade Federal do Paraná. E-mail jinodari@yahoo.com.br
} 
construído para que alguém possa se apresentar como professor de língua inglesa, são os mais variados. Este artigo se propõe a discutir a formação inicial de professores de inglês facilitada pelo exercício da agência híbrida discente/docente resultante de uma experiência de trabalho com a estrutura da referida língua tendo, como ponto de partida, contos curtos da língua inglesa.

A pesquisa a seguir apresentada configura-se em um estudo sobre a própria prática, uma vez que propus uma prática pedagógica e fui responsável pela aplicação de um questionário aos meus alunos após o término da atividade. A proposta foi realizada com alunos de graduação cursando a disciplina de Gramática da Língua Inglesa I, e, dos 06 respondentes, 05 eram alunos de licenciatura em Letras - Inglês e, portanto, estudando para se tornarem professores dessa língua, sendo quatro respondentes do sexo masculino e duas do sexo feminino, com idades variando entre 22 e 32 anos. Como professora com 15 anos de prática em ensino de língua inglesa, e com interesse especial por literatura, não vi melhor forma de expô-los a uma experiência de ensino de língua inglesa com o suporte do texto literário do que fornecer um espaço seguro e restrito para que essa ocorresse nas aulas da referida disciplina.

Optei pelo trabalho com base em textos literários, do gênero conto, por concordar com a ideia defendida por Anna Stetsenko (2010), acerca de ensino e aprendizagem. A autora defende que esse processo precisa integrar o conhecimento revelado da prática social, através da prática social e para a prática social (STETSENKO, 2010, p. 06), onde a literatura serviria como instrumento, ou ainda, ferramenta cultural, para que este conhecimento fosse revelado e compartilhado. Há relatos de outros professores que integraram a literatura em suas aulas de língua inglesa e verificaram que esta prática acrescenta uma nova dimensão ao contexto de ensino de inglês como língua estrangeira (vide PEREIRA, 2008, p. 193), por permitir que os aprendizes de língua inglesa sejam expostos aos aspectos culturais, à questão linguística e a modelos de crescimento pessoal (ao mesmo tempo em que refletem sobre o próprio crescimento) ao lerem textos literários. O gênero conto foi o escolhido por ser exemplificado, normalmente, por textos curtos, de leitura rápida, uma vez que a proposta não solicitava um trabalho intensivo de leitura, ou mesmo de crítica literária. O texto literário foi uma ferramenta pedagógica e cultural nesta proposta.

Como ferramenta cultural, o texto literário apresenta-se inovador ao mesmo tempo em que é representativo da tradição cultural. Além disso, constitui-se em oportunidade de [Digite texto] 
aprendizagem, onde esta é entendida como importante pré-requisito e percurso no desenvolvimento da identidade do indivíduo, uma vez que cada aprendizado transforma a identidade deste (STETSENKO, 2010, p. 13). Nesse caminho, o do desenvolvimento da identidade do indivíduo, faz-se necessário aprender que há diferenças, que é necessário entender diferentes noções de ética, tolerância e vivência em sociedade, como coloca Bhabha (2001, p. 03) ao defender que isso pode ser oportunizado pela aprendizagem de uma língua estrangeira. Em relação à literatura, Bhabha (2001) defende que uma das belezas, e também um dos poderes da literatura, é o de ser representacional de culturas, de maneiras de pensar e agir, representacional de identidades. Ampliando esta compreensão, temos que o texto literário auxilia no desenvolvimento da identidade do indivíduo inserido em um determinado grupo cultural, ou interagindo com outros.

Como futuros professores de língua inglesa, estes profissionais, doravante discentes/docentes, podem ser bem sucedidos se souberem fazer uso das ferramentas culturais a que tem acesso, dentre elas, o texto literário. A seu favor, os futuros professores têm as seguintes situações: eles passaram pelo processo de aprendizagem de uma segunda língua que muitos de seus alunos também enfrentarão, e tem a mesma primeira língua, muitas vezes, que seus alunos, situações estas que se configuram em pontos fortes na prática de sala de aula, segundo McKay (2003, p. 09).

Além disso, mesmo reconhecendo como Jordão bem aponta as "tensões entre literatura e sala de aula, literatura e educação” (2011, p. 287), por restrições da ordem espaço/tempo não abordarei o prisma destas tensões. Reconheço, no entanto, que uma atitude epistemofágica pode ser resultante da combinação de sala de aula, literatura e língua inglesa, onde o termo epistemofagia "alude ao processo de digestão de significados e procedimentos interpretativos, processo no qual tanto o que é digerido quanto quem digere se transformam mutuamente” (JORDÃO, 2011, p. 291). Esta transformação pode ser identificada em algumas das respostas dadas ao questionário aplicado após a realização da proposta de micro aula com o suporte de um texto literário. Estas respostas serão pensadas em relação aos conceitos de hibridismo (BHABHA), agência (FOUCAULT), ensino de literatura (COLLIE \& SLATER) e formação de professores (JORDÃO), mas sem pretender esgotar o assunto.

\section{A proposta e o questionário}


Os discentes/docentes, sujeitos dessa pesquisa, receberam o desafio de propor uma micro-aula de 20 a 30 minutos revisando algum tópico gramatical já abordado em aula com o apoio de um conto, previamente selecionado. Eles foram solicitados a fazer um breve resumo do enredo do conto antes de propor qualquer atividade, que precisou ser inteiramente conduzida em língua inglesa. As atividades foram propostas individualmente e não contaram com a apresentação, ou fornecimento, de um modelo prévio de como ela poderia ser dada, mesmo sabendo que os alunos em formação inicial apresentam uma bagagem constituída por vários exemplos e situações prévias constituintes de sua formação.

Após cada discente/docente apresentar sua micro-aula, eles receberam um questionário aberto com nove questões que deveriam ser respondidas em língua inglesa. As questões versavam sobre a experiência de docência de cada um, ou a falta dessa; sobre uma possível definição para literatura e sua ligação com cultura, e se o discente/docente identificava como possível o trabalho com o texto literário como facilitador no processo de ensino/aprendizagem de uma segunda língua, entre outras; além de solicitar que cada um descrevesse em breves palavras o que havia proposto como atividade a ser realizada por toda a turma e o porquê dessa escolha com base no conto escolhido.

Nem todas as respostas (para um total de 09 questões) serão consideradas para análise nesse texto, uma vez que há restrições da ordem de espaço e tempo a serem consideradas. Por conta dessas restrições, também não farei a descrição das micro-aulas apresentadas. Pretendo fazer um recorte de algumas das respostas e apresentar possíveis entendimentos para estas com suporte teórico, à medida que se fizer necessário, e não primeiramente a teoria e depois a combinação desta com as respostas. Defendo com essa escolha a visão de que teoria e prática andam juntas, se coadunam e se auxiliam em trocas mútuas.

\section{Língua e Cultura}

De acordo com McKay (2003), a cultura exerce um papel significativo no ensino de língua, de duas formas: o conhecimento cultural frequentemente oferece a base para o conteúdo e para os tópicos que são usados nos materiais e nas discussões em sala. Estes conteúdos e tópicos são frequentemente baseados em certos padrões culturais. É aqui que se justifica o uso do texto literário, de gênero conto, para o desenvolvimento de atividades em aulas de língua inglesa. De acordo com Collie \& Slater (2001), um texto literário pode 
transcender delimitações de tempo e cultura e surpreender leitores. Além disso, ele oferece um contexto amplo e vívido no qual personagens de diferentes contextos sociais podem ser representados, outro motivo para considerá-lo útil no processo de aprendizagem de uma língua em função do envolvimento pessoal que pode promover nos aprendizes/leitores. Mesmo em vista de tantas vantagens, a decisão de usar o texto literário em sala de aula depende de algumas escolhas, dentre elas qual texto, como usá-lo, o que será usado e o que não será.

Uma das questões que propus no questionário solicitava que os discentes/docentes se posicionassem quanto à literatura ser ou não benéfica no processo de aquisição de segunda língua, e por quê. Dentre as respostas fornecidas, e vale ressaltar que as respostas analisadas aqui serão reproduzidas ipsis litteris em notas de pé de página, uma delas chama atenção para o fato de que na literatura, a língua está em contexto, estabelecendo também a conexão com o conceito de cultura. $^{2}$

Além disso, os textos literários normalmente não são vistos como tendo sido escritos com propósitos pedagógicos, uma vez que a linguagem não se apresenta de modo a ser trabalhada em determinado nível e, muitas vezes, estes textos são sobre situações corriqueiras, que os alunos enfrentam em seu próprio dia a dia, em seu próprio país. Os textos literários trazem exemplos de variações lexicais e gramaticais de uso de inglês. E, como representante que é da cultura do país que retrata e da língua na qual foi produzido, o texto literário mantém-se como referência constante num mundo de fronteiras mutáveis. Este foi outro aspecto mencionado pelos discentes/docentes em suas respostas.

Ainda outra resposta dada concordou com um dos pressupostos de Collie \& Slater (2001), que apresentarei resumidamente em seguida, de que a literatura auxiliaria os aprendizes a ver o mundo como ele é. ${ }^{3}$ Outros dois respondentes chamaram a atenção para o fato de que a literatura auxiliaria na compreensão da cultura do povo representado por ela, na compreensão do outro e de si mesmo e, também no processo de aquisição de segunda língua, sendo este era o foco da questão. ${ }^{4}$ Ainda outros dois respondentes resgataram a questão da estrutura da língua que é contemplada na produção literária e apresentada como pressuposto que justificaria o uso de textos literários em sala de aula de língua (COLLIE \& SLATER, 2001). ${ }^{5}$

De acordo com Collie \& Slater (2001), há uma gama de abordagens convencionais para se explorar o texto literário em sala de aula e diversificar o repertório de procedimentos. 
Tais abordagens se propõem a trazer certo frescor ao ensino da língua em foco, a estimular o aluno a ter vontade de ler, e a encorajar suas respostas a estas leituras (p. 08). Dentre as diretrizes defendidas pelos autores, estão:

a) que o professor mantenha o interesse e o envolvimento dos alunos pelo uso de uma variedade de atividades centradas nos próprios aprendizes;

b) que a "página impressa" do texto seja suplementada;

c) que as experiências e o conhecimento sejam construídos pelo grupo;

d) que os alunos sejam auxiliados na empreitada de explorar suas próprias respostas à literatura;

e) que a língua alvo seja usada;

f) que haja integração entre língua e literatura.

Estes pressupostos “conversam” com princípios defendidos por Nunan (1989, p. 279) em relação à prática de Ensino Comunicativo de Língua - Communicative Language Teaching (CLT), dentre eles:

a) ênfase no aprender a se comunicar pela interação na língua alvo;

b) oportunidades para que os aprendizes possam focar não apenas na língua, mas também no próprio processo de aprendizagem;

c) o fortalecimento das experiências pessoais dos aprendizes como elementos contributivos para a aprendizagem em sala;

d) uma tentativa de conectar a aprendizagem de língua em sala com a ativação da linguagem fora da sala (in MCKAY, 2003, p. 15).

Mesmo assim, a CLT não foi a única proposta perpassando a prática da referida experiência. Há ainda que se enfatizar que como a CLT não se configura em um método de ensino que, de acordo com Brown (2001, p. 14), seria um plano global para apresentação sistemática da língua com base em uma abordagem selecionada, e sim em uma abordagem, ou seja, pressupostos e crenças acerca da natureza da língua e da aprendizagem desta (RICHARDS \& RODGERS, 1985), seu uso em sala pode ser adequado às necessidades e interesses encontrados. E foi justamente este o cenário que se apresentou na disciplina de Gramática da Língua Inglesa I, onde pressupostos e crenças defendidos por mim, professora do grupo, estavam subjacentes às escolhas feitas e à proposta pedagógica seguida. Uma dessas crenças é a de que literatura e língua se complementam como ferramentas pedagógicas no processo de ensino/aprendizagem de língua. Além disso, defendo a pedagogia da apropriação 
pela experiência do “ver-se” professor como fundamental para garantir espaço de prática da agência docente.

Concordando com Kramsch \& Sullivan, uma pedagogia apropriada deve ser uma pedagogia da apropriação (1996, apud MCKAY, 2003, p. 17). Os aprendizes precisam dominar a gramática e o vocabulário da língua inglesa para interagir de forma eficiente com nativos e não nativos, e ter domínio sobre essas regras de gramática e vocabulário. O texto literário permite o acesso a esses aspectos estruturantes da língua, e uma experiência de ensino de língua inglesa pautada no uso do texto literário possibilitaria uma maior familiaridade do discente/docente com esta rica fonte de conhecimentos, uma "experiência do eu”, como colocaria Foucault.

\section{Experiência e práticas pedagógicas}

A tese de Foucault é a de que estamos em um mundo plural, atualmente, "no qual os fenômenos surgem deslocados, e onde se dão “encontros bastante imprevistos” (2008, p. 310). Para ele, o sentido da experiência é especial - é algo de que se sai transformado. Tomo como base essa compreensão de “experiência” para me referir à proposta que teve como um de seus resultados as respostas fornecidas a um questionário que é o alvo deste artigo. No entanto, percebo também que esta experiência teve pontos de aproximação, principalmente após a consecução, com o conceito proposto pela fenomenologia, "na medida em que nesta se trata de lançar um olhar reflexivo sobre um objeto qualquer do vivido (= a experiência de dar aula com o apoio de um texto literário) para apreender suas significações” (p. XVII, acréscimo meu em itálico).

Os discentes/docentes envolvidos puderam elaborar uma compreensão mais ampla das reais dimensões da prática e de suas consequências ao responder a um questionário que, dentre outras informações, solicitava que eles narrassem o que haviam feito no espaço que lhes foi designado (20 a 30 minutos de uma micro-aula) para explorar a estrutura da língua alvo com base em um conto curto. Além disso, formou-se uma espécie de comunidade de aprendizagem, pela prática pedagógica da mudança de pespectiva ao se abordar um texto literário. De acordo com Lave (1996), a aprendizagem é parte da participação das pessoas em práticas de mudança. "Não há modos de aprendizagem, nesta perspectiva, porque [...] a aprendizagem é uma faceta das comunidades de prática das quais elas são compostas” 
(LAVE, 1996, 150). Nesta perspectiva, a aprendizagem é vista como prática social, ocorrendo em um espaço que pode ser entendido como uma comunidade, ou ainda, uma comunidade de prática social.

Tomando emprestado de Halu (2010) sua compreensão do que seja comunidade de prática, com base nas contribuições do antropólogo Etienne Wenger, temos que as comunidades estão em todo lugar, mas que este conceito não pode ser aplicado a toda e qualquer configuração social. Enquanto ferramenta analítica, o conceito de comunidade não se restringe a uma atividade ou interação específica (uma conversação, por exemplo) e também não cobre configurações amplas como instituições (escolas e empresas, por exemplo) e sistemas (nações e culturas, por exemplo). Ainda nas palavras da pesquisadora,

[d]e acordo com Wenger (1998a, p. 125), nas primeiras não seria possível observar continuidades no tempo e entre as pessoas com relação aos empreendimentos e identidades dos quais são parte; quanto a acompanhar configurações maiores como comunidades, seriam as descontinuidades entre diversos espaços menores, com seus conjuntos de práticas, que seriam perdidas de vista (HALU, 2010, cap. 03).

Gostaria de aludir ao fato de que a experiência de ensino de língua inglesa com o apoio de contos literários possibilitou que os sujeitos envolvidos constituíssem certo saber e se modificassem como seres vivos, na medida em que, constituindo-se como sujeitos racionais, puderam agir sobre si mesmos, e mudar suas condições de vida e a própria vida. Isto tudo possibilitado pelo desafio de sugerir uma atividade para seus colegas cujo foco fosse um aspecto gramatical da língua inglesa e tendo por base um texto literário. Mesmo concordando com Jordão, que “a literatura é assunto de difícil apreensão, tanto em sua estrutura narrativa quanto em seu uso especial da linguagem, que apresenta um alto nível de complexidade” (2005, p. 232), na condução da proposta, optei por enfocar em aspectos estruturais da língua inglesa que pudessem estar mais ao alcance dos discentes/docentes, quais sejam, os aspectos da gramática explorados anteriormente em sala e que poderiam ser resgatados quando da realização da micro-aula, por parte de cada um.

Vale ressaltar que, como professora que conduzia a disciplina, eu não estabeleci outros pré-requisitos que não a observância do tempo (que a atividade durasse cerca de 20-30 minutos), e que o foco da atividade proposta pelos discentes/docentes fosse um aspecto gramatical que já tivesse sido visto na disciplina (dentre eles: tempos verbais, uso dos verbos modais, uso de conectores). Não houve estabelecimento de modelo prévio a ser seguido, e nem a exigência de apresentação de um plano de aula. Com a não apresentação de um modelo [Digite texto] 
prévio (se é que um só poderia ser proposto), buscava-se instigar os alunos a serem criativos e procurarem a melhor forma de trabalhar um aspecto formal da língua inglesa, de maneira contextualizada, e sem acesso a um exemplo que pudesse ser replicado. A aprendizagem de estruturas da língua inglesa, bem como a experiência do fazer docente, se daria pela prática e não com base em códigos de conduta, ou exemplos pré-estabelecidos, mesmo sabendo que cada discente/docente trazia seus próprios modelos de prática pedagógica, tanto em sua condição de discente, quanto de docente, quando este era o caso, confirmando assim que sua agência seria um modelo híbrido, ou seja, não só discente e não só docente quando da escolha da atividade proposta e da condução da micro-aula. Estas práticas se configuram em exemplos da tecnologia do eu.

A “pedagogia tem enfatizado o autodisciplinamento, pelo qual os estudantes devem conservar a si e aos outros sob controle. Seguindo Foucault, as técnicas/práticas que induzem esse comportamento podem ser chamadas de tecnologias do eu” (GORE apud SILVA, 2010, p. 14). Ou ainda, estas práticas seriam aquelas

que permitem aos indivíduos efetuar, por conta própria ou com a ajuda de outros, certo número de operações sobre seu corpo e sua alma, pensamentos, conduta, ou qualquer forma de ser, obtendo assim uma transformação de si mesmos com o fim de alcançar certo estado de felicidade, pureza, sabedoria ou imortalidade (FOUCAULT, 1990, p. 48).

Essa experiência, no entanto, não se constituiu em prática pedagógica libertadora, uma vez que também acredito que não “existem práticas pedagógicas inerentemente libertadoras ou inerentemente repressivas, pois qualquer prática é cooptável e qualquer prática é capaz de tornar-se uma fonte de resistência” (GORE in da SILVA, 2010, p. 15). Isto posto, temos que a pedagogia não é nem uma fonte de dominação, nem uma fonte de resistência. Portanto, assim como Foucault, na condição de autora/professora/pesquisadora não pretendi dar uma resposta à questão acerca de que práticas e discursos pedagógicos são libertadores. Em vez disso, pretendi mostrar como uma proposta envolvendo língua e literatura em língua inglesa pode constituir-se em prática de transformação do sujeito, e espaço de construção de agência pela prática pedagógica.

Por prática pedagógica, entendo aquelas “nas quais o importante não é que se aprenda algo "exterior", um corpo de conhecimentos, mas que se elabore ou reelabore alguma forma de relação reflexiva do “educando” consigo mesmo” (LARROSA in da SILVA, 2010, p. 36, destaques do autor). Não que não se possa aprender "um corpo de conhecimentos”, no caso da [Digite texto] 
disciplina os tópicos gramaticais explorados, mas que este não se constitua o foco da prática, assim como não o foi. É como se as práticas pedagógicas fossem um espaço de possibilidades, um mero entorno favorável, delimitado e organizado para que as pessoas, no caso, os estudantes de Letras, desenvolvam e/ou recuperem as formas de relação consigo mesmos que os caracterizam como professores de língua inglesa.

\section{Sala de aula como espaço e lugar para o exercício da agência}

A micro-aula, conduzida de forma individual pelos discentes/docentes, aqui aparece como um lugar no qual se produzem, se interpretam, e se medeiam histórias pessoais. Lugar e não espaço, pois o geógrafo humanista Yi-Fu Tuan (1983), apresenta definições distintas para estes termos. Lugar é também entendido como “pausa no movimento” (TUAN, 1983, p. 153) e a permanência é um de seus elementos importantes (p. 155). Espaço, por sua vez, é definido de acordo com as relações interpessoais que um ser humano pode estabelecer. É símbolo de amplidão e considerado um sinal comum de liberdade no mundo ocidental. No aspecto positivo, sugere futuro e um convite para a vida, enquanto que no aspecto negativo, espaço e liberdade tornam-se uma ameaça, já que estar aberto e livre significa estar exposto e vulnerável. Nesse sentido, o lugar seria o espaço fechado e humanizado (1983, p. 61), aquele espaço que nos é inteiramente familiar (p. 83). À primeira vista, a experiência de exploração de um aspecto a estrutura da língua inglesa tendo como base um conto constituiu-se como espaço, desafiador e desconhecido, mas a medida que a experiência acontecia e, posteriormente, as narrativas de como se deu foram oportunizadas, ela fez-se lugar, senão de segurança, pelo menos de maior familiaridade, onde a exposição e a vulnerabilidade iniciais deram lugar à reflexão por parte dos discentes/docentes sobre a prática e sobre suas experiências com o ensino/aprendizagem da língua inglesa, experiência essa de agência híbrida, pois ao mesmo tempo em que se viam como docentes, eram discentes.

O que se pretendia com a proposta era

\footnotetext{
definir, formar e transformar um professor reflexivo, capaz de examinar e reexaminar, regular e modificar constantemente tanto sua própria atividade prática quanto, sobretudo, a si mesmo, no contexto dessa prática profissional. As palavraschave desses enfoques sobre a formação do professorado são reflexão, autoregulação, auto-análise, autocrítica, tomada de consciência, autoformação, autonomia, etc. (LARROSA, apud SILVA, 2010, p. 49).
} 
Mesmo estas sendo conclusões acerca de um contexto específico analisado por Larossa, constituem-se aqui em pressupostos plausíveis subjacentes à prática pedagógica realizada. A aula constitui-se como um lugar no qual se aprende a pensar e argumentar sobre questões educativas. "Para dizer de uma maneira próxima ao vocabulário foucaultiano, tratase de produzir e mediar certas “formas de subjetivação” nas quais se estabeleceria e se modificaria a “experiência” que a pessoa tem de si” (LARROSA apud SILVA, 2010, p. 51).

Ao responder um questionário acerca da experiência, os discentes/docentes em processo de formação puderam exteriorizar suas conclusões pelo uso da linguagem escrita. Segundo Larrosa (apud SILVA, 2010, p. 63) “a linguagem é um veículo para a exteriorização de estados subjetivos, algo assim como um canal para extrair para fora, elaborar e tornar públicos certos conteúdos interiores. Na imagem da referência, a linguagem copia a realidade.” Em outras palavras, após a experiência, e tendo participado dos momentos de docência de seus colegas, os discentes/docentes em formação inicial puderam refletir sobre suas escolhas, suas práticas e suas crenças acerca de conceitos tais como: cultura, literatura, leitura e a própria experiência inédita para todos de fazer uso de um texto literário não adaptado para explorar um aspecto estruturante da Língua Inglesa e “apresentar aos outros o que já se” fazia “presente para a própria pessoa.” (ibid)

Levei em consideração que a identidade dos sujeitos da pesquisa é híbrida também no sentido proposto por Jordão (2010), de que a identidade "se engaja com a língua/cultura estrangeira ao mesmo tempo em que interpola sua língua/cultura nativa, constituindo-se enquanto sujeito agente nos processos de construção de sentido” (JORDÃO, 2010, p. 427). Esta identidade híbrida seria facilitadora da prática da agência, onde esta

\footnotetext{
não pressupõe um plano claro e pré-estabelecido para alcançar resultados desejados: agência refere-se à ação construída no processo discursivo de construção de sentidos, na produção e estabelecimento de discursos que definem e categorizam pessoas, ideias, conhecimentos e formas de conhecer. Agência é portanto uma forma de intervir no processo discursivo de construção de sentidos e representações do mundo (JORDÃO, 2010, p. 432).
}

Além disso, essa experiência do híbrido, mais especificamente da fronteira fluida entre discente/docente, foi contra o alardeado discurso colonial que se faz dependente "do conceito de “fixidez” na construção ideológica da alteridade” (BHABHA, 2007, p. 105). Temos, além disso, que a visão que os discentes/docentes passaram a ter do texto literário modificou-se, na 
medida em que verificavam as inúmeras possibilidades de entendimento e de uso deste para o ensino de língua, por exemplo.

Um dos possíveis resultados da experiência, presente quando da redação das respostas ao questionário, seria a reflexão. Como bem colocam Deacon \& Parker (apud SILVA, 2010, p. 99), “[o] encorajamento da reflexão do estudante (docente em formação) sobre seu próprio processo de aprendizagem, assim como um crescente controle sobre ele, é visto como um elemento de diminuição das desigualdades entre professor e aprendiz e como fortalecendo o poder (empowering) dos estudantes para que falem e ajam por si próprios” (primeiro acréscimo em itálico meu). Em outras palavras, ao experimentar situações/desafios e posteriormente terem condições de refletir sobre estas/estes, os discentes/docentes estariam se habilitando a tomar decisões informadas em situações/desafios futuros. Estariam, para alguns estudiosos, exercendo sua agência (termo utilizado na literatura sociológica anglo-saxônica para salientar o elemento ativo da ação humana) docente (= “Que posso fazer?”), mas de forma híbrida, ou seja, como discentes/docentes, que mesmo já tendo alguma prática de ensino, estão em processo de formação.

Reconheco, no entanto, o caráter contingente (transitório) de tal experiência e suas implicações. Em um ambiente seguro, com auxílio e feedback fazia-se possível o exercício da agência docente pela observância de normas e responsabilidades. Temos ainda que

\footnotetext{
o potencial que uma LE tem de transformar nossos procedimentos interpretativos e as maneiras como nos relacionamos com diferentes conhecimentos e formas de conhecer, tem o potencial de nos levar a perceber o mundo de outras maneiras, de vislumbrar formas alternativas de significar e de construir nossas identificações e desidentificações, nosso engajamento com o mundo (JORDÃO, 2006 apud JORDÃO, 2010, p. 434).
}

Outra possível consequência dessa prática pedagógica seria o desarranjo da mesmice de se trabalhar com a gramática da língua inglesa (uma paisagem por vezes monótona) para instigar diferentes formas de ver, ser visto e problematizar a sólida e persistente monotonia de formas rotinizadas (leitura de um conto em língua inglesa e estudo de aspectos gramaticais da referida língua, por vezes) com o objetivo de verificar como seria a nova paisagem resultante da combinação dessas duas. Ainda em relação a esse aspecto, a intenção também era a de não fixar o que se sabe e a forma como devemos agir, uma vez que é altamente desejável que o docente torne-se hábil "em modelar outras possibilidades” (PIGNATELLI in da SILVA, 
2010, p. 149) e considerar a condicional “e se fosse de outra forma?” (ibid) como condição presente em sua prática.

Outro aspecto resultante da proposta pedagógica adotada seria a tensão dialética entre teoria, prática e experiência, “uma tensão necessária para o aprendizado crítico” (McLAREN, 1997, p. 189). Dentre os seis sujeitos participantes da proposta e que responderam o questionário, cinco possuíam experiência prévia no ensino de língua inglesa (informação solicitada pela questão 02), mas não haviam ainda trabalhado com o texto literário para ensino de língua.

Para eles, a sala de aula de língua apresentou-se como espaço (ainda não lugar), como ambiente tenso, mas também

como lócus potencial para a transformação dos processos interpretativos de alunos e professores, como espaço de confronto com o legitimado, onde não apenas se assimilam conhecimentos, mas principalmente onde esses conhecimentos são transformados e, no processo, geram outros conhecimentos e formas de conhecer (JORDÃO, 2010, p. 291).

Em relação à questão de número 08, que solicitava que os respondentes se posicionássem quanto à utilidade do texto literário para a aula de língua, todos os respondentes apresentaram-se a favor, mesmo levantando aspectos diferentes para justificarem suas respostas. Dois respondentes chamaram a atenção para o nível linguístico dos alunos ${ }^{6}$ que deveria ser considerado ao se propor alguma leitura de texto literário. É interessante observar que um destes respondentes chamou a atenção para o fato de que o texto literário não apresenta a língua hermeticamente preparada para ser trabalhada em aula de língua inglesa, como acontece em livros de gramática. Relevante observar isso porque a proposta de trabalho solicitava justamente que os alunos preparassem um exercício com foco gramatical que pudesse ser abordado tendo como base um conto literário, o que pode levar à conclusão de que a proposta pedagógica constituiu-se em desafio para os discentes/docentes envolvidos, um desafio significativo, não mera reprodução de conhecimentos prévios.

Quanto à experiência de usar um conto literário para explorar um aspecto gramatical que os discentes/docentes foram solicitados a descrever na última questão (questão 09) do questionário, todos afirmaram que esta mostrou-se válida para que conhecimentos da estrutura da língua inglesa pudessem ser trabalhados, apesar de difícil. ${ }^{7}$ Cabe ressaltar que outro objetivo subjacente à prática pedagógica realizada pelos discentes/docentes dizia respeito ao 
letramento crítico, principalmente no que se refere ao "protagonismo do aprendiz” (MATTOS \& VALÉRIO, 2010, p. 140) enfatizado por esta proposta.

Este aspecto, o do letramento crítico, conversa diretamente com o ensino comunicativo de língua, uma vez que há flexibilidade de papéis que facilitam o processo de aprendizagem, pois ambos permitem ao aprendiz (discente/docente) tomar iniciativas, exercitar sua intuição e criatividade e sentir-se mais confiante para engajar-se em atividades em sala de aula, possibilitando-lhe também apropriar-se de seu processo de aprendizagem (MATTOS \& VALÉRIO, 2010, p. 141). Ao juntar o letramento crítico ao ensino comunicativo de língua, com vistas ao estabelecimento de um lugar (na perspectiva proposta por TUAN (1983), ou seja, de ambiente humanizado e familiar) para prática pedagógica pretendi que cada discente/docente fosse levado a diversos níveis de reflexão, onde ele

\begin{abstract}
voltar-se-ia para si mesmo a fim de apoderar-se de seu processo de aprendizagem; voltar-se-ia para o texto a fim de dominar seus conteúdos semânticos, léxicosistêmicos, discursivos e pragmáticos; e voltar-se-ia, ainda, para o cenário sóciohistórico de sua interação com o texto, a fim de apoderar-se de sua própria história e de traçá-la de acordo com suas aspirações (MATTOS \& VALÉRIO, 2010, p. 149).
\end{abstract}

Concordando com MILLER (2009), entendo que "parte de nossa responsabilidade (como formadores de professores) é estar prontos para atribuir agência a estudantes (discentes/docentes) e parte é educar suas capacidades de atribuição.” (p. 196, acréscimos em itálico meus), principalmente por observar que, com exceção de alguns poucos casos, normalmente, os discentes/docentes se vêem acuados na academia, com medo de exercer sua agência se não houver um espaço (na perspectiva de TUAN) legitimado e reservado para tal. Além disso, as respostas dadas pelos discentes/docentes se configuraram em suplementos informativos para especulações (tomando emprestada a expressão de MILLER, 2009) sobre agência, hibridismo e formação de professores.

\title{
Considerações finais
}

Não pretendi esgotar as possibilidades de entendimento cabíveis em relação a esta experiência, muito menos em relação às respostas fornecidas pelos discentes/docentes envolvidos na pesquisa, pois estas estrapolariam o escopo escolhido para este artigo. Pretendi, no entanto, apresentar a proposta de se trabalhar com texto literário, onde a língua inglesa é apresentada "sem disfarces" e de forma contextualizada, como uma proposta pedagógica [Digite texto] 
plausível, factível e executável, apesar de todos os desafios inerentes a ela. Proposta esta que se configura em ferramenta pedagógica valiosa e que possibilita o exercício da agência docente/discente em um lugar favorável contruido pelo professor em conjunto com seus alunos.

\section{Bibliografia}

BHABHA, Homi. O Local da Cultura. Trad. De Myriam Ávila, Eliana Lourenço de Lima Reis e Gláucia Renate Gonçalves. Belo Horizonte: Editora UFMG, 2007.

BHABHA, Homi. The right to narrate: Interview with Homi Bhabha. By Kerry Chance. March, 2001. p. 01-07.

BROWN, Douglas H. Teaching by Principles. An interactive Approach to Language Pedagogy. 2nd ed. San Francisco State University: Longman, 2001.

COLLIE, Joanne \& SLATER, Stephen. Literature in the language classroom. Cambridge: Cambridge University Press, 2001 [1987].

CRYSTAL, David. English as a global language. 2. ed. Cambridge: Cambridge University Press, 2010 [1997].

DEACON, Roger \& PARKER, Ben. Educação como Sujeição e como Recusa. In: da SILVA, Tomaz Tadeu. O Sujeito da Educação: estudos Foucaultianos. Petrópolis: Vozes, 2010. p. 97-110.

FOUCAULT, Michel. Arqueologia das ciências e história dos sistemas de pensamento. Trad. Elisa Monteiro. 2. ed. Rio de Janeiro: Forense Universitária, 2008.

GORE, Jennifer M. Foucault e Educação: Fascinantes Desafios. In: da SILVA, Tomaz Tadeu. O Sujeito da Educação: estudos Foucaultianos. Petrópolis: Vozes, 2010. p. 09-20.

HALU, R. C. Formação de formadoras de professoras de língua inglesa em contexto de formação continuada. Tese (Doutorado em Letras) - Universidade Federal do Paraná. Curitiba, 2010.

JORDÃO, Clarissa M. Da educação literária: elocubrações epistemofágicas de uma professora sobre o ensino/aprendizagem de procedimentos interpretativos na literatura. In: BONNICI, Thomas; FLORY, Alexandre Villibor \& PRADO, Márcio Roberto do. Margens instáveis: tensões entre teoria, crítica e história da literatura. Maringá: Eduem, 2011. p. 287295.

JORDÃO, Clarissa M. A posição de professor de inglês no Brasil: hibridismo, identidade e agência. Revista Letras \& Letras, Uberlândia, Minas Gerais, v. 26, n. 2, p. 427-442, jul./dez. 2010. 
JORDÃO, Clarissa M. A construção do sujeito na educação literária: um passeio pela crítica literária e os papéis do bom leitor. IN: TOMITCH, Lêda M. B. et al. (orgs.) Literaturas de língua inglesa. visões e revisões. Florianópolis: Insular, 2005. p. 231-243.

LARROSA, Jorge. Tecnologias do Eu e Educação. In: da SILVA, Tomaz Tadeu. O Sujeito da Educação: estudos Foucaultianos. Petrópolis: Vozes, 2010. p. 35-86.

LAVE, Jean. Teaching, as learning, in practice. Mind, Culture, and Activity, Berkeley, v. 3, n. 3, p. 149-164, 1996.

MATTOS, Andréa Machado de Almeida \& VALÉRIO, Kátia Modesto. Letramento crítico e ensino comunicativo: lacunas e interseções. Revista brasileira de linguística aplicada, Belo Horizonte, v. 10, n. 1, p. 135-158, 2010.

McKAY, Sandra L. Toward an appropriate EIL pedagogy: re-examining common ELT assumptions. International Journal of Applied Linguistics, San Francisco, v. 13, n. 1, p. 01-22, 2003.

McLAREN Peter. A vida nas escolas: uma introdução à pedagogia crítica nos fundamentos da educação. 2. ed. Porto Alegre: ARTMED, 1997. [1977].

MILLER, Carolyn R. Estudos sobre gênero textual, agência e tecnologia. Recife: Editora Universitária da UFPE, 2009.

NUNAN, David. Communicative tasks and the language curriculum TESOL Quarterly, v. 25, n. 2, p. 27-295, 1989.

PEREIRA, Rosamaria Reo. Literature in the Language Classroom. Revista Crop., São Paulo, n., 13 p. 192-204, 2008.

PIGNATELLI, Frank. “Que posso fazer? Foucault e a Questão da Liberdade e da Agência Docente”. In: da SILVA, Tomaz Tadeu. O Sujeito da Educação: estudos Foucaultianos. Petrópolis: Vozes, 2010. p. 127-154.

STETSENKO, Anna. Teaching-learning and development as activist projects of historical Becoming: expanding Vygotsky's approach to pedagogy. Pedagogies: An International Journal, New York, v. 5, n. 1, p. 06-16, Jan/Mar, 2010.

TUAN, Yi-Fu. Espaço e lugar: a perspectiva da experiência. Trad. Lívia de Oliveira São Paulo: DIFEL, 1983.

1 Artigo redigido para fins de avaliação parcial na disciplina de Linguística Aplicada III - Programa de Pósgraduação em Letras - UFPR, sob supervisão da professora Dra. Clarissa Menezes Jordão.

2 Resposta original à pergunta - Do you think literature is beneficial in a second language acquisition process? Why/ Why not?: "It is for those that advocate that language acquisition is not only a technical relation, but also cultural. But even for those that do not it is important because it is language in context."

[Digite texto] 
3 Resposta original: "Sure! Literature helps learners understand how the foreign language works. It helps them start thinking on the foreign language. And it helps them understand how native speakers see the same world we live in."

4 Resposta original: "Yes, because it help us to improve knowledge about other cultures and about ourselves." Resposta original: "Yes, I do. Literature is the artistical and most beautiful use of language. Also, it allows students to get in contact with the culture behind the language."

5 Resposta original: "Yes, I think literature is necessary. It's essencial to learner understand how language work."

6 Resposta original: "Yes, it can be useful if learner can understand it."Resposta original: "In a intermediate level I believe it is because the context and it also helps to retain the subjects as mnemonic auxiliary. It is also a true language and not that laboratorial (clinic) language from grammar books."

7 Resposta original: "I suggested an activity based on all forms of the past tense. The main reason for suggesting that kind of activity was the text that used that structure. It was a pretty good activity, a good way to help us students to learn how to behave in a classroom as teachers. (...)” Resposta original: “(...) The activity is very challenging, not only for those that intend to be teachers, and I feel that every grow-up classes should be done based upon short stories, because there is no grammar topic that can't be related to it. (...)” 